\title{
Using Modern Information and Communication Technologies to Support the Access to Cultural Values
}

\author{
Cristian Ciurea ${ }^{1}$, Lorena Pocatilu ${ }^{2}$, Florin Gheorghe Filip ${ }^{3}$ \\ ${ }^{1,2}$ Bucharest University of Economic Studies \\ 3 The Romanian Academy \\ ${ }^{1}$ ciurea@ie.ase.ro, ${ }^{2}$ lorena.pocatilu@ie.ase.ro, ${ }^{3}$ ffilip@acad.ro
}

\begin{abstract}
The objective of our paper is to highlight the connection and reciprocal influences between two important fields of human activities, namely information and communication technology (ICT) sector, on the one hand and the cultural one, on the other hand. We describe several concepts, such as virtual exhibitions, active digital resources, creative industries, and digital assets to facilitate a better understanding of Europe's cultural heritage and its economic potential. Based on authors' practical experience, it is presented the analysis of the economic impact of ICTs on creative industries as well as their technological impact upon cultural institutions. In particular, we present proposals of ICTs solutions for the development of the cultural field to reveal the advantages of each type of implementation (web and mobile).
\end{abstract}

Keywords: Cultural heritage, information tools and platforms, smart city, sustainable development, virtual exhibitions.

\section{Introduction}

The last decade brought strong influences from information and communication technologies (ICTs) to human activities and the whole society. Nowadays, people need STEM (Science, Technology, Engineering, and Mathematics) skills to face the challenges of modern jobs. In the near future, we expect that such new skills will enable remote work by using modern ICTs. However, the negative effects of digitalization on workers' well-being, including mental stress, should be addressed as well in order to estimate long-term evolutions.

Because many people are currently living in ever more numerous smart cities and are enjoying the advantages of modern information and communication technologies, human behavior has been changed. People interact physically to a less 
extent - instead, they prefer to use electronic means of communication. Still, technology is the solution to tackle loneliness and to bring people together, by offering dedicated applications. Discussing about smart cities, nowadays "smart" has been replaced by "digital". In (Borda and Bowen, 2017), it is defined the concept of smart cultural heritage, as a combination of smart cities and visualization technologies used to access and promote cultural heritage, since cultural heritage has the potential to play a significant role in the development of smart cities.

Europe's rich culture should be made known, especially to young people. Storytelling is nowadays the most effective solution to add value to cultural heritage collections, especially when they are accessed and displayed using modern information and communication because they construct narrative experiences for visitors in the digital age (Wong, 2015). Modern digital storytelling is also used to address educational objectives. Virtual exhibitions (VE) represent the best way to unfold or disclose the story of every cultural object, attractively presented with the support of new technologies. A virtual exhibition in our age has a very big responsibility to offer information, knowledge and educational content to people. A virtual exhibition is a smart solution for empowering cultural institutions and, at the same time, is a real support for the future development of cities. In (Batagan, 2011), it is emphasized that in order to improve the quality and performance of cities it is recommended to involve cultural institutions to implement intelligent solutions efficiently.

The rest of the paper is organized as follows. The next section presents the opportunities created by modern information and communication technologies, including Internet of things/services, in the cultural sector. In the third section various aspects of technology impact on the cultural sector are highlighted. The fourth section contains a presentation of possible approaches, tools, and platforms. A practical tool and an example of its application within the Library of the Romanian Academy are described too. Several statistics concerning the impact of the virtual exhibition described in the previous section, and paper conclusions are eventually presented.

\section{Internet of Things and Cultural Institutions}

Many cultural institutions around the world that are grouped under the general name GLAM (Galleries, Libraries, Archives and Museums) preserve famous works in cultural collections that attract tourists who travel especially to see them. For example, the Rijksmuseum in Amsterdam is well-known for the Rembrandt's Night Watch painting, the Louvre in Paris for Da Vinci's Mona Lisa and Belvedere Museum in Vienna for Klimt's Kiss. Some works have been deteriorated over time and must be restored and preserved (Turskis et al., 2017), (Vodopivec et al., 2014). In the case of Rembrandt's Night Watch, the physical restoration process was livestreamed from Amsterdam's Rijksmuseum to be watched by everyone interested 
and for this process to be monitored step by step (Boffey, 2019). Various virtual restoration techniques for cultural heritage protection and long-term preservation are presented in (Zhou et al., 2012). Standards and norms of exhibition digitization, as well as virtual exhibitions of digital museums are described in the same paper.

An effective preservation method is to use advanced digitization, so that digital copies of cultural objects are created in order to be preserved, included in virtual exhibitions, and accessed by the large public from any location in the world at any time. Digitization is the process through which tangible cultural objects are transformed into intangible or virtual ones (Ahmad, 2006). Virtual exhibitions should include interactive and virtual and augmented reality-based immersive features that could potentially increase the participation of their visitors (Wojciechowski et al., 2004; Jung et al., 2016).

The target groups are very important when designing and creating a virtual exhibition because curators and programmers should have in mind the end-users' goals, particular interests, expertise in terms of cultural collections and digital abilities, and their behavior in exploring digital exhibitions. If the target groups are limited to a certain number of visitors, then the success of a virtual exhibition is also reduced. The target groups should comprise various researchers, industries, small and medium enterprises (SMEs), academics, policymakers, and public authorities. All of them define the audience of a virtual exhibition.

A virtual exhibition can be designed as a responsive web application, available online from any type of device (desktop, laptop, smartphone, tablet, etc.), or as a native mobile application available on mobile devices (smartphone, tablet, smartwatch) that runs the operating system to which the application is developed (Android, iOS, Windows Phone etc.). Mobile virtual exhibitions capitalize on the portability of mobile devices and their ability to be used from anywhere and anytime (Wong, 2015). Thanks to accelerometers and gyroscopes sensors, mobile devices can deliver an enhanced personalized experience for visitors of a physical exhibition that can combine elements from a virtual and a physical exhibition Virtual exhibitions can be enhanced with elements of mobile augmented reality systems (MARS) to replace the real-world objects with simulated ones, in order to deliver the best user experience (Kavakli, 2015).

Today, all over the world are many virtual exhibitions like Agora Gallery (https://www.agora-gallery.com/exhibitions/virtual_tours.aspx), Caroun Art Gallery (http://www.caroun.com/CAG/V-Exhibitions/2019/00-V-Exhibitions-2019.html),

British Library virtual exhibitions (https:/www.bl.uk/discover-and-learn/onlineexhibitions). These are only a few examples, but the trend in this field is in exponential growing. One of the main benefits of the virtual exhibitions is that cultural heritage becomes more accessible to every people and the barriers of their location or their financial will disappear.

Internet of Things (IoT) will exert a big impact on people in the near future and will 
influence also the cultural field evolution. Important cultural heritage objects, such as monuments, sculptures, statues, and so on can be equipped with sensors and beacon technology (Benouaret and Lenne, 2015; Dhanyatha et al., 2019) that will make possible the direct interaction between the cultural object and the visitor approaching it. For example, if a visitor installs on his/her smartphone a dedicated mobile application and goes to travel and explore a new city, or a museum, when he is in the vicinity of an important statue or monument, or a displayed object of art which can be of interest for him, the visitor will directly receive a notification from the mobile application which will communicate with computing device installed on that cultural heritage object. An indirect interaction is provided by the GPS feature with which is equipped the visitor's mobile device, and the descriptive content can be downloaded from a remote server or cloud. In this case, the Google location services play an important role in delivering cultural content, combined with Google Maps facilities in order to recommend to the user other point of interests around his location.

In (Amaro and Oliveira, 2019), it is described and evaluated an IoT system in order to understand its potential to support playful intergenerational engagement in creating and exploring cultural heritage collections and learning material about cultural heritage objects. In such a system, smart objects become pervasive and able to provide information and services to visitors through data sharing features, standardized and interoperable communication protocols. In the case of libraries and museums, that preserve old and rare books, manuscripts, and artefacts, the IoT infrastructure can maintain and regulate the temperature, humidity and illumination, in order to control the conservation conditions and notify the curators, through intelligent alerts, when sensors detect values outside the established intervals (Bhattacharya, 2019).

In (Dobre and Xhafa, 2014), it is assumed that smart cities of the future will rely not only on sensors, but also on a large number of devices that will integrate their data into intelligent platforms used to analyze the habits and situations of the people and large communities of a city. The adoption of the most challenging technologies, like Internet of Things and Internet of Services (IoS), can represent the progress towards unified ICT platforms for a variety of applications within the large framework of smart cities. The IoT paradigm supports the transition from a closed world, where an object is characterized by a descriptor, to an open world, where smart objects interact with the surrounding environment (Chianese et al., 2015).

\section{The Economic Impact of ICTs}

Fadli and AlSaeed (2019) describe the design and development of an innovative digital platform to enable real-time preservation and protection of cultural heritage, facilitating the collaboration between several professionals from different activity fields. The cultural heritage is seen as a prerequisite for sustainable development of 
cultural institutions, thanks to rapid technological changes, which are creating great opportunities for promoting cultural heritage at home and abroad (Fanea-Ivanovici, 2018).

Pop et al. (2019) introduced the concept of cultural sustainability, which is considered to bring economic, social, and environmental benefits to cultural institutions. Similar views were presented by Filip et al. (2015).

We should clearly differentiate the concepts "digitization" and "digitalization". While the first one means to scan and create digital copies of documents, the second one refers to the degree of implementation of information and communication technologies (ICTs) in a specific field of activity. Employees of cultural institutions need to acquire new skills related to the digital transformation of their jobs. In the future, due to the impact of technology, some jobs will disappear and new ones will be created. For example, a curator of a physical exhibition should become a digital curator of a virtual exhibition.

According to the research presented in (UFI, 2019), the economic impact of ICTs should be divided into direct impact, indirect impact, and induced impact, which are expressed in terms of economic output, including business sales, GDP (Gross Domestic Product) and jobs.

Based on an analysis made by The Global Association of the Exhibition Industry (UFI, 2019), in 2018, in approximately 32,000 global exhibitions around the world, a number of 303 million visitors across more than 180 countries came up. In terms of business sales, these exhibitions generated more than 115.9 billion euros. They supported 1.3 million direct jobs globally and generated 68.7 billion euros of direct GDP.

In terms of indirect and induced impacts, the analyzed exhibitions supported a total global economic impact in 2018 of 275.1 billion euros of business sales, 3.2 million jobs and 167.2 billion euros, representing their contribution to GDP. As a conclusion, the global exhibitions analyzed have generated more business sales than many other large economic sectors, including machine tools and medical and surgical equipment (UFI, 2019).

Table 1: Visitors' number of global exhibitions in 2018 (in million) (UFI, 2019)

\begin{tabular}{|c|c|}
\hline Region & No. of visitors \\
\hline Europe & 112.0 \\
\hline North America & 91.2 \\
\hline Asia/Pacific & 81.5 \\
\hline Central and South America & 9.9 \\
\hline Middle East & 6.3 \\
\hline Africa & 2.1 \\
\hline
\end{tabular}

As shown in Table 1, the highest number of visitors in the analyzed exhibitions is 
to be found in Europe, but regions such as North America and Asia have also registered big numbers of visitors.

In terms of total economic outputs (business sales, impact on GDP), statistics reveal that North America has registered the highest volume (around 119 billion euros), but countries from Europe accumulated around 92 billion euros, which is a significant volume (see Table 2).

Table 2: Economic impacts by region in 2018 (in billion euros) (UFI, 2019)

\begin{tabular}{|c|c|}
\hline Region & Output \\
\hline Europe & 92.27 \\
\hline North America & 118.83 \\
\hline Asia/Pacific & 56.58 \\
\hline Central and South America & 4.12 \\
\hline Middle East & 2.39 \\
\hline Africa & 0.94 \\
\hline
\end{tabular}

In the case of total employment by region, in terms of the total number of jobs created as a result of the exhibitions analyzed, North America is also the representative region with 1,302 thousands of jobs; while Asia/Pacific and Europe have generated similar values (see Table 3 ).

Table 3: Number of jobs created in 2018, by region (UFI, 2019)

\begin{tabular}{|c|c|}
\hline Region & No. of jobs \\
\hline Europe & 824 \\
\hline North America & 1302 \\
\hline Asia/Pacific & 980 \\
\hline Central and South America & 85 \\
\hline Middle East & 31 \\
\hline Africa & 19 \\
\hline
\end{tabular}

The smallest number of jobs created following the sampled exhibitions is found in Africa, totaling a number of 19,000 jobs.

\section{Conclusion and Proposals}

Due to the development of mobile devices and technologies (nowadays we have the best and most accurate maps of the world), the decrease in costs brought on by the air-travel market liberalization and the increase of accommodations reservations via dedicated platforms, the concept of "over-tourism" emerged (Bershidsky, 2019). A major European Union report (Peeters et al., 2018) found places like Venice, Prague, Paris, and Barcelona with an average density about three times as high as their regular density. 
Nowadays, cultural institutions ought to bring their heritage collections online, as digital assets, in order to retrieve information from historical data collections and disseminate the memory of cultural heritage (Ciurea and Filip, 2019). There are many recent projects about the importance of cultural heritage digitization to create high-quality 3D digital versions of cultural heritage sites and collections at potential risk of damage from conflict or natural disaster (Brzezicki et al., 2019). One useful feature of a virtual exhibition is the possibility to explore digital images in detail, by applying zooming tools, so that the visitor would be able to discover particular details that the person cannot notice when visiting the physical exhibition. Of course, this implies high quality digitization of physical objects. The Library of Congress has recently published a digital collection of its rare Persian manuscripts, an archive including 700 years of history and representing a free resource on diverse religious, national, linguistic, and cultural traditions (Jones, 2020). The advanced digitization concept refers to the scanning and photographing of the test corpus at a high resolution, to ensure the best quality of images representing the digital copies. The advanced digitization will play a significant role in the development of active digital resources that will stimulate the economic development of creative industries and will have a scientific impact upon cultural institutions. This will lead to a better promotion and dissemination of Europe's cultural heritage.

In order to implement strategies for digital cultural content development, a multiple criteria decision making (MCDM) approach is described by Yeh (2017) for evaluating and selecting the proper digital content industry.

The practical impact of ICTs on cultural institutions can be measured by the number of software products such as virtual exhibitions, mobile applications that have been developed to increase the research level, the publication degree, the creation of new ideas, and the implementation of new research projects.

\subsection{Tools}

One of the recently published mobile applications in Google Play store is Google Arts and Culture (https://artsandculture.google.com), which allows the indirect interaction by providing the possibility to virtually visit the most known exhibits, zoom in on artworks to the smallest detail and navigate through thousands of photos, videos, and manuscripts. By using Google Arts and Culture application, the user can be his own curator; he can create his own cultural collections, and share them with other users. Google Arts and Culture collaborated with more than 1,200 museums, art galleries, and cultural institutions from 70 countries in order to make their exhibits available online. The mobile application has many interesting features, such as zoom views, virtual reality mechanisms; it offers the possibility to explore cultural exhibits by filtering them by color or time, to find museums and cultural events around, to translate details about exhibits in other languages, and so on.

One of the ICTs solutions for cultural field development is the development of 
virtual exhibitions using the MOVIO tool (https://www.athenaplus.eu/index.php?en/211/movio), which allows the presentation of cultural heritage collections comprehensively and attractively. The format of the virtual exhibition will be a website accessible online from any type of device, presenting collections belonging to one or more cultural institutions. Figure 1 below shows the technical diagram of MOVIO platform.

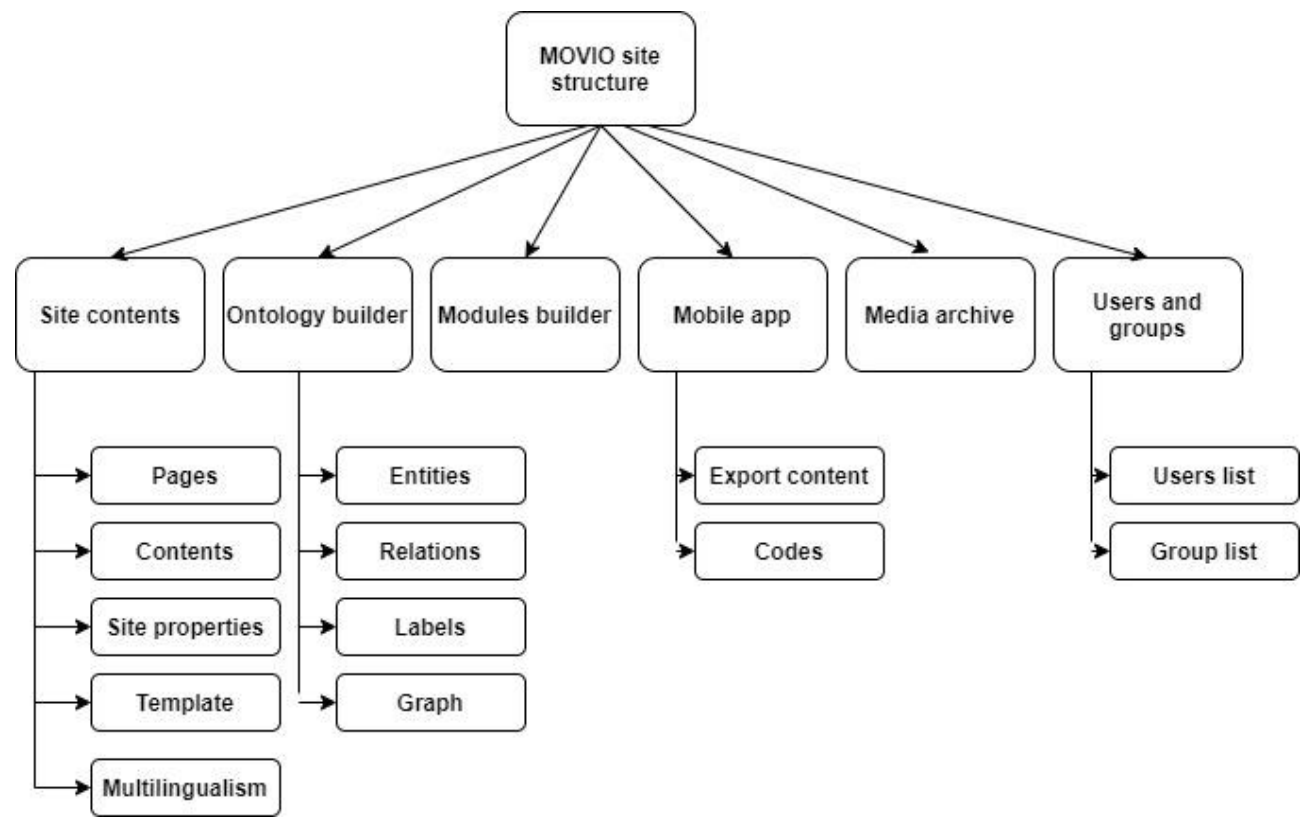

Fig. 1: Site structure of the MOVIO tool

One of the cultural institutions that have already implemented ten virtual exhibitions using the MOVIO tool is the Romanian Academy Library, where there can be found the expertise in developing Android mobile applications designed for the promotion of cultural heritage collections. Some of the virtual exhibitions already implemented have been described in previous scientific papers published in international journals (Ciurea and Filip, 2019; Ciurea and Filip, 2019b).

\subsection{An Example}

Figure 2 shows a screen capture from the most recent virtual exhibition, developed with MOVIO, based on a physical exhibition created at the Romanian Academy Library entitled "Cultural Itineraries: Romania-France" (http://movio.biblacad.ro/FRANTA/ ).

A virtual exhibition can also be implemented as an Android mobile application presenting cultural heritage collections, which will help the potentially interested public to locate collections belonging to different cultural institutions and to attract new real visitors of these institutions. 
The implementation of virtual exhibitions as native mobile applications should not be neglected taking into account the number of people owning a smartphone today. In 2014, around $97 \%$ of the whole world population was using a mobile phone and in 2019 a number of 3.3 billion people had a smartphone (Muto and Yamano, 2009).

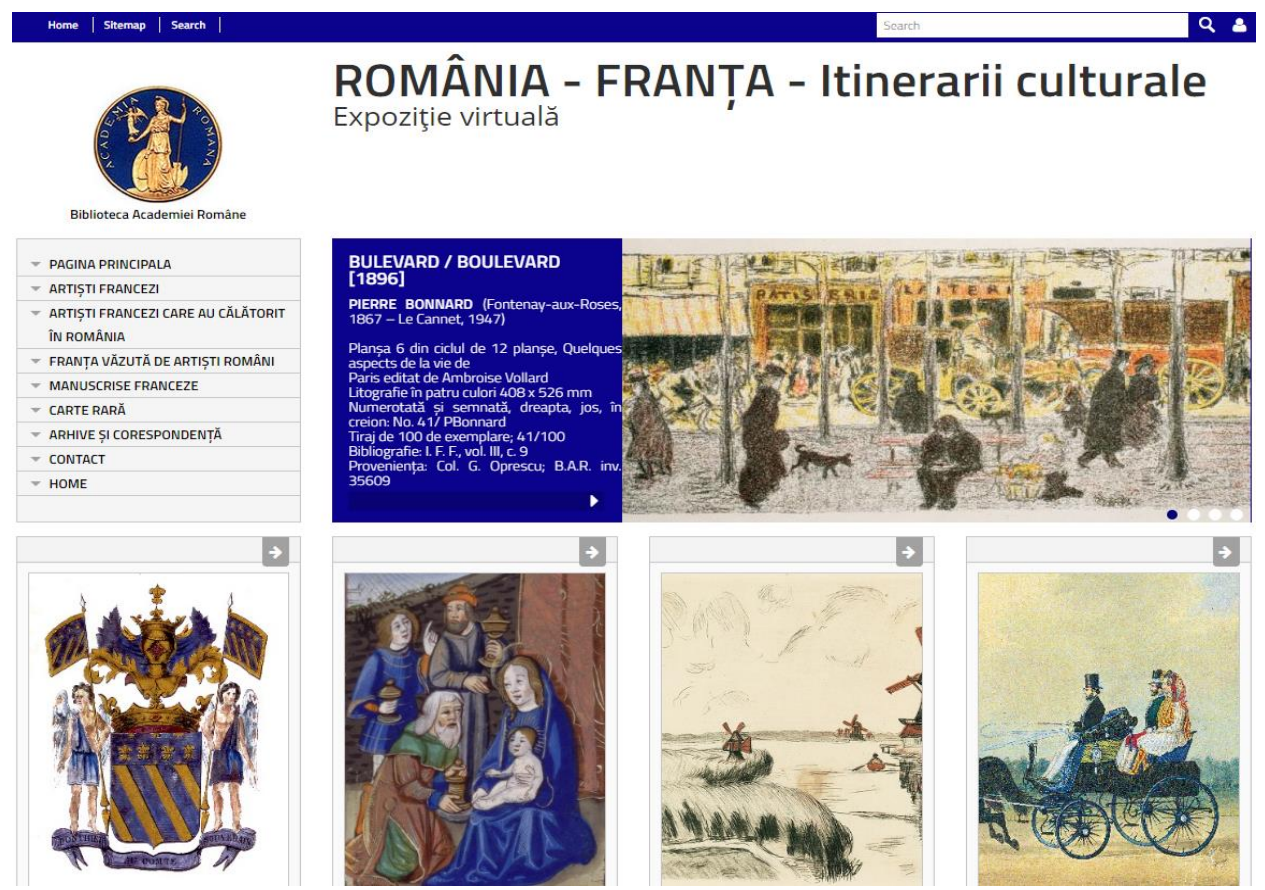

Fig. 2: A virtual exhibition created with MOVIO

The scope of a virtual exhibition is to enhance the "storytelling" dimension of this kind of project by implementing an application available both in web and mobile formats that presents cultural content in various ways. This should be seen as an extension of what people can do with the cultural heritage collections after they have been digitized and aggregated on a dedicated platform.

Starting from this approach, we suggest the diagram from Figure 3, applicable in the cultural field to express the correlation between the implementation of virtual exhibitions and the revenues of cultural institutions. The number of virtual exhibitions implemented in a cultural institution should have an influence on the number of visitors and the monthly revenues of the cultural institutions.

Based on the Figure 3 diagram, the followings conclusions can be drawn:

- the access improvement to cultural heritage collections and their promotion and use are already subject of international recommendations;

- the digitization process of cultural collections is still lacking, only $10 \%$ of the European cultural heritage being digitized at this moment (Ciurea and Filip, 
2019);

- the cooperation of various factors involved, including governments, cultural institutions, IT companies, content aggregators, and so on is necessary and, consequently, collaborative decisions ( Filip et al., 2017) are to be made;

- the evolutions of the cultural sector cannot be separated from the global evolution of the current country and the whole world.

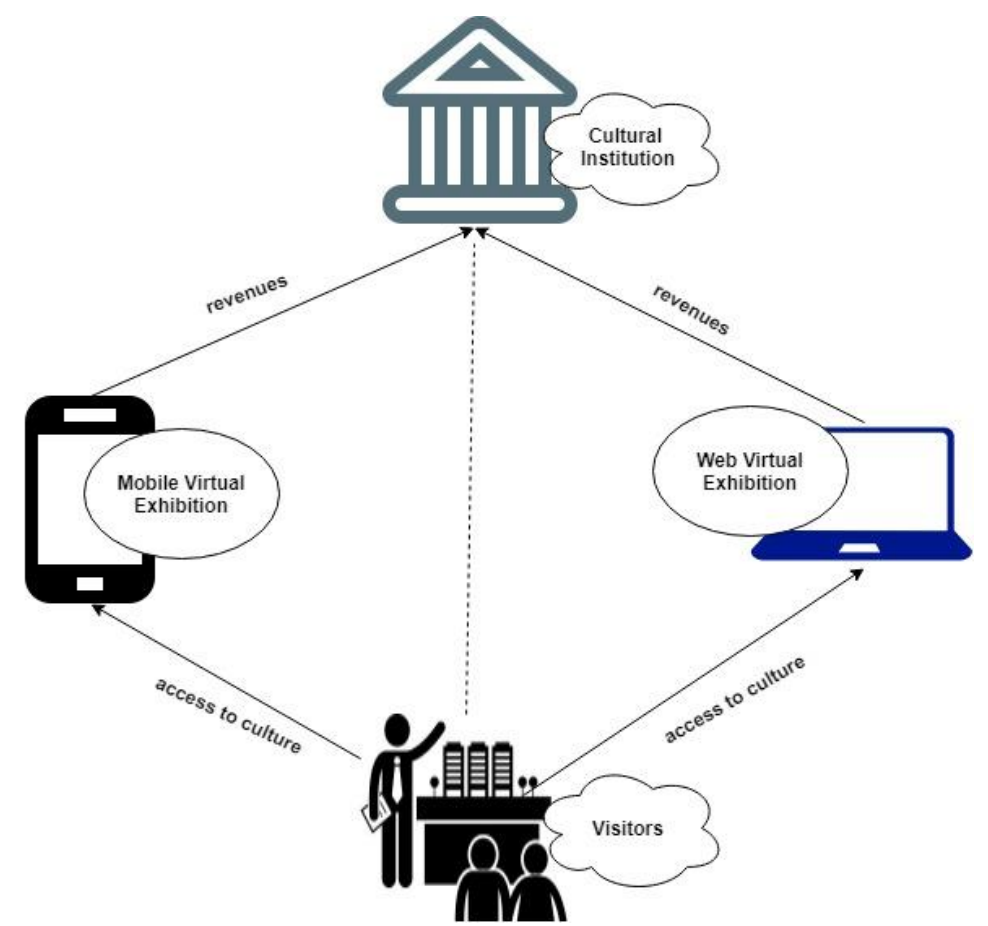

Fig. 3: Influence of virtual exhibitions on the number of visitors and revenues

\subsection{Virtual Exhibition Platforms}

Another ICTs solution for the development of the cultural field is the creation of a platform that will be semantically enriched - translated, tagged and indexed in such a way that only relevant material is called up when needed. It will be automatically plotted against geo-historical maps (through metadata and text analysis) and linked to explanatory material of different levels of complexity. If we consider the linguistic barriers, then crowd transcription and translation modules will be developed setting the stage for the future progress of automatic tools. At the level of images, the gap between pixel level and perceptible form can be complicated in the material used as test-corpus, as forms are often themselves objects of representation via deformations and multiplications of traditional patterns of representation. Analysis of objects and forms will be available in order to link images and map the way new styles appear against specific cultural visual paradigms. Ultimately, the tools created will be able to map and reveal precisely how European-wide 
movements have determined the evolutions and transformations of major cultures through their circulation and influences.

\subsection{Choosing a Tool}

There are a lot of software tools used nowadays to create and develop virtual exhibitions, many of them being free and open source. Depending on the type of virtual exhibition, online or mobile, we can discuss about IDEs (Integrated Development Environment) and mobile platforms. Based on the analysis presented in (OEDB, 2020) and our experience, the major software tools, free and open source, used to create virtual exhibitions are:

- CollectionSpace, http://www.collectionspace.org, is an open-source collections management application for museums, libraries that have special collections. It supports multiple metadata schemas including Dublin Core.

- Collective Access, http://collectiveaccess.org, is a cataloguing tool for museums, archives and digital collections, which has a web component, called Pawtucket.

- MOVIO, developed during a research project named Athena Plus (https://www.athenaplus.eu) meant for being used especially by the libraries and museums participating in that project.

- Omeka, http://omeka.org, which helps to create attractive virtual exhibitions using templates and page layouts, without having to adjust code. Omeka uses Dublin Core metadata and offers customizable item type cataloguing.

- Open Exhibits, http://openexhibits.org, is a multi-touch, multi-user toolkit that allows to create interactive virtual exhibitions.

- Pachyderm, http://pachyderm.nmc.org, is an easy-to-use multimedia authoring tool, allowing to create interactive, Flash-based presentations that can include images, sounds, video, and text.

The decision of choosing and using the best tool is not taken only for the people involved in developing virtual exhibitions, but also to other people with authority in the organization. The subjects of interest in the decision-making process represents the characteristics of the assessed tool that are taken into consideration at the moment of choosing the most adequate one. When a metric is associated to a subject of interest, we obtain an evaluation criterion. The values (named also attribute levels) obtained for the metrics associated to evaluation criteria are introduced in MADM (Multi-Attribute Decision Making) and hybrid MADM models (Zavadskas et al., 2016) to be solved by using the available algorithms to filter the alternatives and obtain a ranking (Ciurea and Filip, 2015; Zavadskas et al., 2019).

The main evaluation criteria for selecting the best ICT platform can be grouped into three subsets as follows (Filip, 2012):

- the adequacy of the method; 
- the quality of the informatics implementation;

- the way of acquisition, post delivery assistance, and comfortable usage.

Table 4 presents the results of a group of experts regarding the evaluation criteria used for selecting the best ICT platforms in order to develop virtual exhibitions where the figures represent the marks provided by experts (in the range 1 to 5$)$.

Table 4: Comparative analysis of major software tools in developing a virtual exhibition

(Ciurea and Filip, 2015)

\begin{tabular}{|c|c|c|c|c|c|c|}
\hline $\begin{array}{c}\text { Evaluation } \\
\text { criteria }\end{array}$ & Omeka & $\begin{array}{c}\text { Collective } \\
\text { Access }\end{array}$ & MOVIO & $\begin{array}{c}\text { Collection } \\
\text { Space }\end{array}$ & $\begin{array}{c}\text { Open } \\
\text { Exhibits }\end{array}$ & Pachyderm \\
\hline $\begin{array}{c}\text { adequacy of } \\
\text { the method }\end{array}$ & 5 & 4 & 5 & 4 & 5 & 4 \\
\hline $\begin{array}{c}\text { quality of } \\
\text { the } \\
\text { informatics } \\
\text { implementa } \\
\text { tion }\end{array}$ & 5 & 4 & 4 & 4 & 5 & 5 \\
\hline $\begin{array}{c}\text { way of } \\
\text { acquisition } \\
\text { and usage }\end{array}$ & 5 & 5 & 4 & 5 & 5 & 5 \\
\hline
\end{tabular}

The comparison of software tools presented in Table 4 represents the points of view of the group of experts in terms of the opportunity to create a virtual exhibition using these free and open source tools, based on the evaluation criteria presented above.

As presented in (Borangiu et al., 2020), the digital transformation will radically change the Industry of the Future through digital twins that represent abstract entities specific for the manufacturing domain: products, orders and resources. These digital twins are the equivalent of virtual exhibitions in the cultural field.

\section{Statistics and Data analysis for a Practical Virtual Exhibition}

Based on the data collected by Google Analytics in the period of time 11 April - 11 July 2019 for the Ferdinand I virtual exhibition (http://movio.biblacad.ro/FERDINAND/), implemented at the Romanian Academy Library, the Figure 5 below shows the percentages of access by type of devices and by country. 

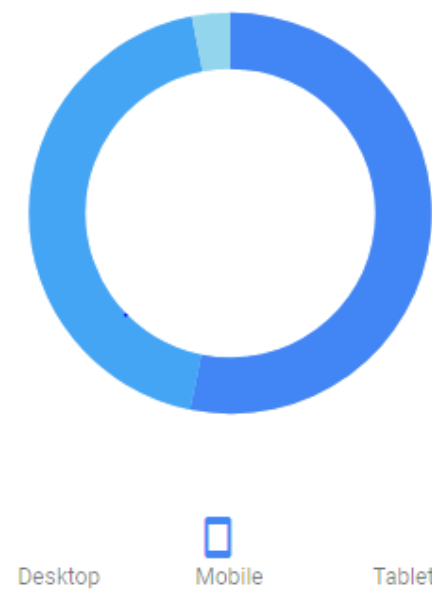

$53.2 \%$

$\downarrow 17.0 \%$

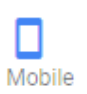

$43.7 \%$

$\uparrow 15.6 \%$
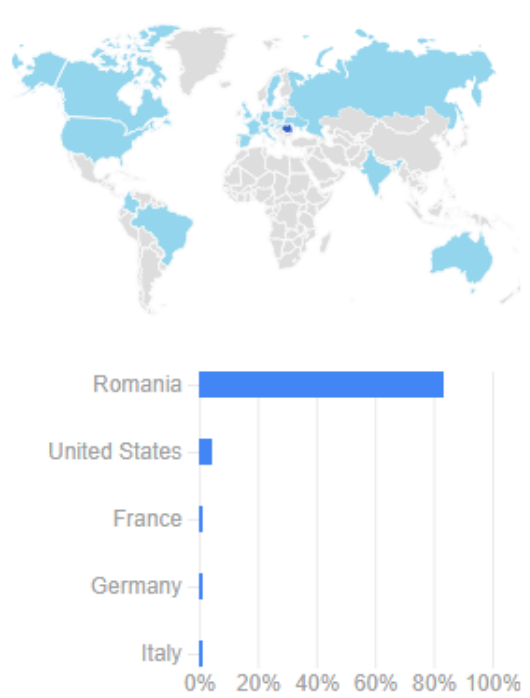

Last 90 days $>$ MOBILE OVERVIEW > Last 90 days - LOCATION OVERVIEW >

Fig. 4: Statistics by type of devices and by users' country

Table 5: Statistics concerning screen resolutions

\begin{tabular}{|c|c|c|c|c|c|}
\hline \multicolumn{2}{|c|}{ Period } & \multicolumn{2}{c|}{ 11 July 2019} & \multicolumn{2}{c|}{11 December 2019} \\
\hline No. & Screen Resolution & Users & $\%$ Users & Users & $\%$ Users \\
\hline 1 & $360 \times 640$ & 111 & $35.58 \%$ & 71 & $25.18 \%$ \\
\hline 2 & $360 \times 740$ & 31 & $9.94 \%$ & 21 & $7.45 \%$ \\
\hline 3 & $375 \times 667$ & 20 & $6.41 \%$ & 22 & $7.80 \%$ \\
\hline 4 & $412 \times 846$ & 17 & $5.45 \%$ & 16 & $5.67 \%$ \\
\hline 5 & $2000 \times 2000$ & 15 & $4.81 \%$ & 26 & $9.22 \%$ \\
\hline 6 & $360 \times 720$ & 13 & $4.17 \%$ & 11 & $3.90 \%$ \\
\hline 7 & $320 \times 568$ & 11 & $3.53 \%$ & - & - \\
\hline 8 & $375 \times 812$ & 11 & $3.53 \%$ & 15 & $5.32 \%$ \\
\hline 9 & $412 \times 732$ & 9 & $2.88 \%$ & 10 & $3.55 \%$ \\
\hline 10 & $320 \times 570$ & 8 & $2.56 \%$ & - & - \\
\hline 11 & $360 \times 780$ & - & - & 10 & $3.55 \%$ \\
\hline 12 & $360 \times 760$ & - & - & 9 & $3.19 \%$ \\
\hline
\end{tabular}

As seen from Figure 4, the number of accesses from desktop and mobile devices is almost equivalent, but when analyzing the mobile accesses we notice that most visits were made from smartphones and only $3 \%$ from tablets.

Table 5 below presents various screen resolutions that were used when 
accessing the virtual exhibition using a mobile device in two periods of time (11 July 2018 - 11 July 2019 and 11 July 2019 - 11 December 2019). The most used resolution was 360 x 640 pixels, which is the standard screen resolution for many smartphones.

This piece of information is very useful for virtual exhibitions developers, in order to better design the user interface, so that to display the important elements in the best way possible.

The statistics regarding the most used operating systems from which the virtual exhibition was accessed in in two periods of time (11 July 2018 - 11 July 2019 and 11 July 2019 - 11 December 2019) demonstrates that Windows and Android are the most used operating system from all access events (see details in Table 6).

Table 6: Statistics regarding operating systems

\begin{tabular}{|c|c|c|c|c|c|}
\hline \multicolumn{2}{|c|}{ Period } & \multicolumn{2}{|c|}{ 11 July 2019} & \multicolumn{2}{c|}{ 11 December 2019 } \\
\hline No. & Operating system & Users & $\%$ Users & Users & $\%$ Users \\
\hline 1 & Windows & 447 & $57.23 \%$ & 309 & $51.24 \%$ \\
\hline 2 & Android & 233 & $29.83 \%$ & 195 & $32.34 \%$ \\
\hline 3 & iOS & 73 & $9.35 \%$ & 87 & $14.43 \%$ \\
\hline 4 & Macintosh & 18 & $2.30 \%$ & 5 & $0.83 \%$ \\
\hline 5 & Linux & 5 & $0.64 \%$ & 6 & $1.00 \%$ \\
\hline 6 & Windows Phone & 2 & $0.26 \%$ & - & - \\
\hline 7 & BlackBerry & 1 & $0.13 \%$ & - & - \\
\hline
\end{tabular}

When analyzing the data concerning the countries from which the virtual exhibition named Ferdinand I was accessed in two periods of time (11 July 2018 11 July 2019 and 11 July 2019 - 11 December 2019), we notice that 84\% of the visits were made from Romania, because the exhibition has a strong national character, since it was organized with the occasion of the 100th anniversary of Romania.

Even if the exhibition content is in the Romanian language, Table 7 shows the list of countries and the number of distinct users that have accessed this application.

It can be seen from Table 7 that $18 \%$ of the visitors are outside the Romania. Figure 5 highlights the distributions of users from other countries than Romania. Remarkably, a significant number of users come from the United States, presumably Romanian people that live there. Even if in Spain there is a large community of Romanian citizens, the number of visitors is not so high. This analysis highlights that it is very important to promote a virtual exhibition. 
Table 7: Statistics by users' country

\begin{tabular}{|c|c|c|c|c|c|}
\hline \multicolumn{2}{|c|}{ Period } & \multicolumn{2}{c|}{ 11 July 2019 } & \multicolumn{2}{c|}{ 11 December 2019 } \\
\hline No. & Region & Users & \%Users & Users & $\%$ Users \\
\hline 1 & Romania & 656 & $83.99 \%$ & 498 & $82.45 \%$ \\
\hline 2 & United States & 28 & $3.59 \%$ & 33 & $5.46 \%$ \\
\hline 3 & Rep. Moldova & 16 & $2.05 \%$ & 18 & $2.98 \%$ \\
\hline 4 & Italy & 11 & $1.41 \%$ & 10 & $1.66 \%$ \\
\hline 5 & Germany & 7 & $0.90 \%$ & 7 & $1.16 \%$ \\
\hline 6 & France & 7 & $0.90 \%$ & 3 & $0.50 \%$ \\
\hline 7 & Canada & 6 & $0.77 \%$ & - & - \\
\hline 8 & United Kingdom & 5 & $0.64 \%$ & 7 & $1.16 \%$ \\
\hline 9 & India & 4 & $0.51 \%$ & - & - \\
\hline 10 & Poland & 4 & $0.51 \%$ & - & - \\
\hline 11 & Spain & - & - & 3 & $0.50 \%$ \\
\hline 12 & Serbia & - & - & 3 & $0.50 \%$ \\
\hline 13 & Russia & - & - & 3 & $0.50 \%$ \\
\hline
\end{tabular}

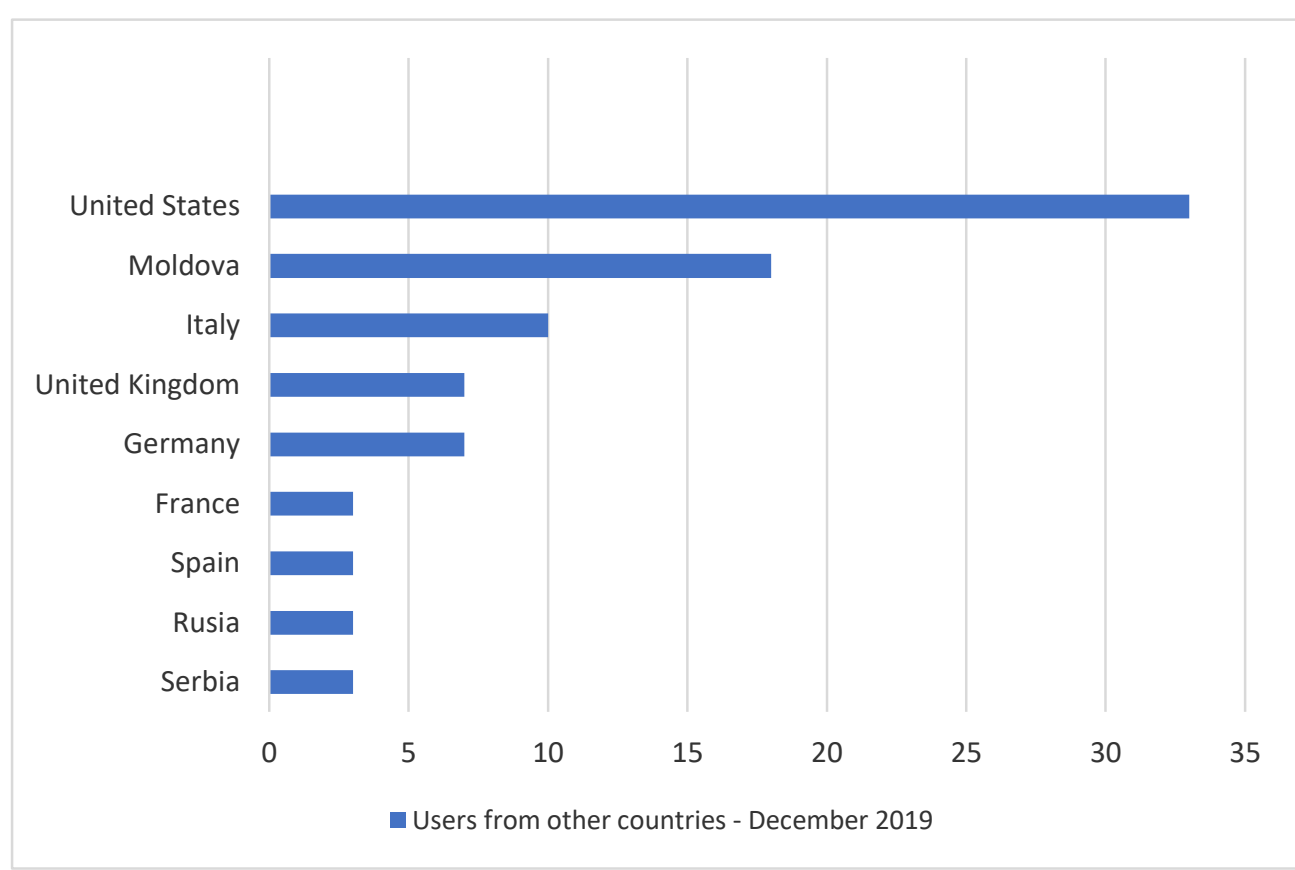

Fig. 5: User distribution by country (December 2019)

\section{Conclusions}

Virtual exhibitions are a real support for cultural institutions development and their general mission is to improve the quality of life and to develop the society. They are 
centers of knowledge and sources of information that contribute to create new values.

The collaboration of experts from the cultural sector and specialists of modern information and communication technologies will lead to connecting the tangible and intangible cultural objects, by using digitization methods linked to active sensor networks or semantic web technologies.

The communication, coordination and cooperation of multiple actors from different activity fields (cultural and ICTs), the concepts of active digital resources or digital assets that can be reused to implement attractive virtual exhibitions will determine the economic development of creative industries and this will lead to a good scientific impact for cultural institutions.

By retrieving useful information from historical data collections and by promoting and employing cultural collections with the support of modern ICTs, Europe's cultural heritage will be better promoted. Europe's cultural heritage is assessed as an unexploited economic resource, necessary for the long-term development of European cultural institutions.

\section{References}

Ahmad, Y. (2006). The Scope and Definitions of Heritage: From Tangible to Intangible, International Journal of Heritage Studies, 12(3), 292-300, DOI: http://dx.doi.org/10.1080/13527250600604639

Amaro, A. C., and Oliveira, L. (2019). IoT for Playful Intergenerational Learning about Cultural Heritage: The LOCUS Approach, Proceedings of the 5th international conference on information and communication technologies for ageing well and e-health (ict4awe 2019), 282-288.

Bătăgan, L. (2011). Smart Cities and Sustainability Models, Informatica Economică, 15(3), 80-87.

Bershidsky, L. (2019). Prepare for Another Summer of Overtourism, Bloomberg, June 9, Available at: https://www.bloomberg.com/opinion/articles/2019-0609/europe-s-top-vacation-sites-need-options-to-fight-overcrowding, Accessed on 24th January, 2020.

Benouaret, I., and Lenne, D. (2015). Personalizing the Museum Experience through Context-Aware Recommendations, 2015 IEEE International Conference on Systems, Man, and Cybernetics, Kowloon, 743-748.

Bhattacharya, I. (2019). Scientific Technology: Relevance and Role of 'Internet of Things' (IoT) in Museums, Conference Paper, Available at: 
https://www.researchgate.net/publication/335490801, Accessed on 14th February 2020.

Boffey, D. (2019). Like a military operation: restoration of Rembrandt's Night Watch begins, The Guardian, 5 July, Available at: https://www.theguardian.com/artanddesign/2019/jul/05/restoration-rembrandtnight-watch-begins-rijksmuseum-amsterdam, Accessed on 24th January, 2020

Borangiu, T., Morariu, O., Răileanu, S., Trentesaux, D., Leitão, P., and Barata, J. (2020). Digital transformation of manufacturing. Industry of the Future with CyberPhysical Production Systems, Romanian Journal of Information Science and Technology (ROMJIST), 23(1), 3-37.

Borda, A., and Bowen, J. P. (2017). Smart Cities and Cultural Heritage - A Review of Developments and Future Opportunities, Proceedings of Electronic Visualisation and the Arts (EVA 2017), 11 - 13 July, London, UK, 9-18, DOI: http://dx.doi.org/10.14236/ewic/EVA2017.2, Accessed on 24th January, 2020.

Brzezicki, F., Ansara, R. R., Awad, R., Quintero, M. S., Abdulac, S., Lavenir, M.-L., Tung, B., Ristevski, J., and Pelletier, M. (2019). Project Anqa: Presenting The Built Heritage of Damascus, Syria Through Digitally-Assisted Storytelling, The International Archives of the Photogrammetry, Remote Sensing and Spatial Information Sciences, Volume IV-2/W6, 27th CIPA International Symposium "Documenting the past for a better future", 1-5 September 2019, Avila, Spain.

Chianese, A., Piccialli, F., and Riccio, G. (2015). The TrUST project: improving the fruition of historical centres through Smart Objects, The 5th International Conference on Current and Future Trends of Information and Communication Technologies in Healthcare (ICTH 2015), Procedia Computer Science, 63, 159-164.

Ciurea, C., Filip, and F. G. (2015). Multi-Criteria Analysis in Choosing IT\&C Platforms for Creative Digital Works, Uncommon Culture, 6(2), 211-223.

Ciurea, C., and Filip, F. G. (2019). The Globalization Impact on Creative Industries and Cultural Heritage: A Case Study, Creativity Studies, 12(2), 211-223.

Ciurea, C., and Filip, F. G. (2019b). Virtual Exhibitions in Cultural Institutions: Useful Applications of Informatics in a Knowledge-based Society, Studies in Informatics and Control, 28(1), 55-64. 
Dhanyatha. N. S., Rhea C., Sridevi P., Swetha H. L., and Madhu B. K. (2019). A Survey on Systems Using Beacon Technology, International Research Journal of Engineering and Technology (IRJET), 6(4), 4048-4052.

Dobre, C., and Xhafa, F. (2014). Intelligent Services for Big Data Science, Future Generation Computer Systems, 37, 267-281.

Fadli, F., and Alsaeed, M. (2019). Digitizing Vanishing Architectural Heritage; The Design and Development of Qatar Historic Buildings Information Modeling [QHBIM] Platform, Sustainability, 11(2501).

Fanea-Ivanovici, M. (2018). Culture as a Prerequisite for Sustainable Development. An Investigation into the Process of Cultural Content Digitisation in Romania, Sustainability, 10(1859).

Filip, F. G. (2012). A Decision-Making Perspective for Designing and Building Information Systems, International Journal of Computers Communications \& Control, 7(2), 264-272.

Filip, F. G., Ciurea, C., Dragomirescu, H., and Ivan, I. (2015). Cultural Heritage and Modern Information and Communication Technologies, Technological and Economic Development of Economy, 21(3), 441-459.

Filip, F. G., Zamfirescu, C. B, and Ciurea, C. (2017). Computer Supported Collaborative Decision-making. Springer.

Jones, J. (2019). 700 Years of Persian Manuscripts Now Digitized and Available Online, Open Culture, April 5th, 2019, Available at: http://www.openculture.com/2019/04/persian-manuscripts-spanning-700-yearsnow-digitized-and-available-online.html, Accessed on 24th January, 2020.

Jung, T., Tom Dieck, M.C., Lee, H., and Chung, N. (2016). Effects of Virtual Reality and Augmented Reality on Visitor Experiences in Museum. In: Inversini A., Schegg R. (eds) Information and Communication Technologies in Tourism, Springer, 621-635.

Kavakli, M. (2015). A people-centric framework for mobile augmented reality systems (MARS) design: ArcHIVE 4Any, Human-centric Computing and Information Sciences, 5-37, DOI: https://doi.org/10.1186/s13673-015-0055-9. 
Muto, M., and Yamano, T. (2009). The impact of mobile phone coverage expansion on market participation: Panel data evidence from Uganda, World development, 37(12), 1887-1896.

OEDB (2020). Open Education Database, 5 Free and Open Source Tools for Creating Digital Exhibitions, 2020, Available at: https://oedb.org/ilibrarian/5-freeand-open-source-tools-for-creating-digital-exhibitions/, Accessed on 9th February 2020 .

Peeters, P., Gössling, S., Klijs, J., Milano, C., Novelli, M., Dijkmans, C., Eijgelaar, E., Hartman, S., Heslinga, J., Isaac, R., Mitas, O., Moretti, S., Nawijn, J., Papp, B., and Postma, A. (2018). Research for TRAN Committee - Overtourism: impact and possible policy responses, European Parliament, Policy Department for Structural and Cohesion Policies, Brussels, (Availableat:https://pure.buas.nl/ws/files/710245/Peeters_ea_research_for_TRAN_c ommittee_overtourism_2018.pdf, Accessed on 18 March 2020).

Pop, I.L., Borza, A., Buiga, A., Ighian, D., and Toader, R. (2019). Achieving Cultural Sustainability in Museums: A Step Toward Sustainable Development, Sustainability, 11(970).

Turskis, Z., Morkunaite, Z., and Kutut, V. (2017). A hybrid multiple criteria evaluation method of ranking of cultural heritage structures for renovation projects, International Journal of Strategic Property Management, 21(3), 318-329, DOI: http://dx.doi.org/10.3846/1648715X.2017.1325782.

UFI. (2019). The Global Association of the Exhibition Industry, Global Economic Impact of Exhibitions, April 2019, Available at: https://www.ufi.org/wpcontent/uploads/2019/04/Global-Economic-Impact-of-Exhibitions b.pdf, Accessed on 24th January, 2020.

Vodopivec, B., Žarnić, R., Tamošaitienè, J., Lazauskas, M., and Šelih, J. (2014). Renovation priority ranking by multi-criteria assessment of architectural heritage: the case of castles, International Journal of Strategic Property Management, 18(1), 88-100, DOI: $\underline{\text { http://dx.doi.org/10.3846/1648715X.2014.889771. }}$

Wojciechowski, R., Walczak, K., White, M., Cellary, W. (2004). Building Virtual and Augmented Reality museum exhibitions. In Proceedings of the ninth international conference on $3 D$ Web technology (Web3D '04). Association for Computing Machinery, New York, NY, USA, pp. 135-144. DOI: https://doi.org/10.1145/985040.985060 
Wong, A. (2015). The whole story, and then some: 'digital storytelling' in evolving museum practice, Museums and the Web 2015 (MW2015), 08-11 April, Chicago, USA, Available at: https://mw2015.museumsandtheweb.com/paper/the-wholestory-and-then-some-digital-storytelling-in-evolving-museum-practice/, Accessed on 24th January, 2020.

Yeh, C. C. (2017). Using a hybrid model to evaluate development strategies for digital content, Technological and Economic Development of Economy, 23(6), 795809.

Zavadskas E. K., Govindan K., Antucheviciene J., andTurskis Z. (2016). Hybrid multiple criteria decision-making methods: a review of applications for sustainability issues, Economic Research-Ekonomska Istraživanja, 29(1), 857-887, DOI: http://dx.doi.org/10.1080/1331677X.2016.1237302

Zavadskas, E. K., Antucheviciene, J., and Chatterjee, P. (2019). Multiple-criteria decision-making (MCDM) techniques for business processes information management, Information, 10(4), DOI: https://doi.org/10.3390/info10010004.

Zhou, M., Geng, G., and Wu, Z. (2012). Digital Preservation Technology for Cultural Heritage, Springer-Verlag. 